\title{
Vocational Rehabilitation of Mild Mentally Challenged Adults
}

\author{
Shony Mathew P. J ${ }^{1 *}$, Dr. Vidhya Ravindranadan ${ }^{2}$
}

\section{ABSTRACT}

Vocational Rehabilitation is the part of continuous and coordinated process of rehabilitation which involves the guidance, vocational training and selective placement designed to enable a differently abled person to secure and retain suitable employment. The present study analyzes impact of vocational training in the competencies of mild mentally challenged adults. The sample for the study consists of 8 mild mentally challenged adults between the age of 18 -30 years. An individualized vocational curriculum is developed and the vocational training courses provided training in computer, stitching, embroidery, office assistance and identity card making. Pre test-post test design has been used in order to understand the influence of intervention. For this purpose Behavioral Assessment Scales for Adult Living - Mental Retardation (BASAL MR) and Personal data sheet has been used. The results indicate that vocational training has great impact in developing competencies of mild mentally challenged.

Keywords: Mentally Challenged, Vocational Training, Competencies.

American Association of Intellectual and Developmental Disabilities (2010) defined intellectual disability as characterized by significant limitations both in intellectual functioning and in adaptive behavior, which covers a range of everyday social and practical skills. This disability originates before the age of 18 (Schalock, R. L. et. al. 2010). It stresses the abilities and assets of mentally challenged adults rather than their deficits (Gargiulo, 2015). In this definition, the disability is seen as a state of functioning rather than an inherent trait. Intellectual disability is not a disease as generally believed, but it is a state. The terms like intellectual disability, developmental disorder, developmental delays, and intellectual disability etc. are used to avoid the derogatory connotations associated with the word mental retardation (Winzer, 1993). The term mental retardation is a stigmatizing and highly offensive label (Harris, 2006). $2.21 \%$ Indian population is differently abled (censusindia.gov.in, 2011). The mentally retarded population is $1,505,24$. They constitute $5.6 \%$ of differently abled population. Percentage of disabled persons in India has increased both in rural and urban areas during last decade and proportion of disabled population is higher in rural areas. Even though they have deficit in intelligence and adaptive behaviours, we cannot keep them within the four walls of house or of an institution. By providing adequate training, they can become productive individuals.

\footnotetext{
${ }^{1}$ Research and Development Centre, Bharathiar University, Coimbatore

${ }^{2}$ Department of Psychology, Union Christian College, Aluva, Kerala.

*Corresponding Author (C) 2015 I S Mathew, V Ravidranadan; licensee IJIP. This is an Open Access Research distributed under the terms of the Creative Commons Attribution License (http://creativecommons.org/licenses/by/2.0), which permits unrestricted use, distribution, and reproduction in any Medium, provided the original work is properly cited.
} 
Therefore, vocational training of mentally challenged people is inevitable. (Mukhopadhyay, 2010).

The Person with Disabilities act (Equal Opportunities, Protection of Rights and Full Participation Act, 1995) is a major milestone in Indian legislation for differently abled persons. In India, attention to the vocational training of the differently abled has gained importance since the enactment of this law. Even though, many vocational training centres are present in Indian Territory, but the concern for transition from school to work has not been serious. National Institute of Mentally Handicapped had developed NIMH Transition model for vocational training and employment for mentally challenged adults to suit to Indian context. It includes four stages and they are school training, planning for the transition, placing in employment and ongoing support services. The stage of planning for the transition involves community assessment, vocational assessment and individualized transition plan. The ongoing support services are extensive vocational training, provide additional remediation in academic subjects, to lead them towards independent living and attain quality of life, to organise social warming exercises for better acceptability in the work community, and to teach necessary skills needed to succeed in carrier (Thressiakutty \& Govinda Rao, 2001).

Braun, Alissop \& Lollar, (2006) conducted a study to test the hypothesis that the difficulties young adults with developmental disabilities have in obtaining adult social roles are not inevitable consequences of their childhood impairment. The results suggested three aspects:

attaining adult social roles varies by impairment type and severity. Experiencing activity limitations partially mediate the relationship between impairment and adult social roles. Attending post secondary education increases the likelihood of attaining markers of adulthood. The study concluded that intervention to reduce activity limitations and to develop strategies to increase attendance in post secondary education may increase the likelihood for the acquisition of adult social roles among young adults with childhood impairment.

\section{Statement of the Problem}

The present study intends to analyze the impact of vocational training in the competencies of mild mentally challenged adults. Thus the problem under investigation is entitled as "Vocational rehabilitation of mild mentally challenged adults".

\section{Operational Definitions of Key Terms}

Vocational Rehabilitation is the part of the continuous and coordinated process of rehabilitation which involves the guidance, vocational training and selective placement designed to enable a disabled person to secure and retain suitable employment.

Competency means ability of an individual to do a job properly. It is the capacity, skill or ability to do something correctly or efficiently. In the present study, competencies include personal care 
and appearance, food management, household tasks and responsibility, community and leisure, sexuality, work, social communication and functional literacy.

Mild mentally challenged adults are people with typical level of social and communication skills during the preschool years, have minimal impairment in sensory motor areas, and often are not distinguishable from children without mental retardation until a later age (Grossman, H. J.1983). Their IQ level is 50-55 to 70 approximately. During their adult years, they usually achieve social and vocational skills adequate for minimum self support, but may need supervision, guidance, and assistance, especially under unusual social or economic stress (DSM -IV-TR).

\section{METHODOLOGY}

Objectives: to understand the impact of vocational training in the competencies of mild mentally challenged adults.

Hypotheses: There will be significant mean difference between pre test and post test scores after Vocational training.

Sample: The sample consisted of 8 mild mentally challenged male adults undergoing vocational rehabilitation at Ernakulam District in Kerala state. Among the samples all were males. The subjects belong to the age group of 18 to 30 years. The sample was taken with random representation to Christians, Hindu and Muslims from matched socio-economic background. All were having disability certificate from medical board of Kerala state.

Intervention Procedure: Students are admitted after completing $12^{\text {th }}$ standard and interview is conducted for the candidates and parents to assess parental input, anecdotal input, past records, general physical health, interests and aptitude of trainee. The trainee is functionally assessed by using BASAL - MR. An individualized vocational curriculum plan is developed in collaboration with special educator, psychologist, vocational instructor, social worker and rehabilitation professional for a period of one academic year. In the first three months, special attention is given to develop basic academic skills of reading, writing and calculating. The most appropriate training is provided for each candidate according to their aptitude and abilities. The vocational training courses provided training in computer, stitching, embroidery, office assistance and identity card making. The specific skill training and independent living skills are provided with respect to the abilities and requirement based on the curriculum.

Assessment: The baseline assessment is conducted in the initial period, as soon as the admission is taken and before the commencement of vocational training in order to assess the present level of functioning. Vocational rehabilitation course is started as intervention. In addition to specific job skill training, students are also should be prepared to manage money, use of public transport and sexuality, social communication, community and leisure activities. Specific skill training was given in computer, stitching, embroidery, office assistance and identity card making. The 
trained vocational instructors provide training to students following baseline assessment. The first post test assessment was conducted after 3 months training. The second post test assessment was conducted after six months and the third post assessment was conducted after nine months.

Instrument: Behavioral Assessment Scales for Adult Living - Mental Retardation(BASAL -MR) is the assessment scale developed by Reeta Peshawaria, D. K.Menon, don Bailey, Debra Skinner, Rahul Ganguly and Ch. Rajshekar of National Institute of Mentally Handicapped in 2000. It has been developed for use with adult persons having mental retardation. BASAL -MR can be used as a curriculum guide for training adults in work settings, home and community living and training in personal independence. The scale is divided in to two parts; part A (competencies) and part B (behaviours). For the purpose of this study the results on Part A only focussed; which includes 8 domains and they are personal care and appearance, food management, household tasks and responsibility, community and leisure, sexuality, work, functional literacy and social communication.

Statistical Procedure: Data were analyzed using spss; paired sample t-test has been conducted to know the difference between the pre and post test scores of the participants.

\section{RESULT AND DISCUSSION}

Paired sample t-test has been done to compare the post test scores of subjects with their baseline scores. The results of paired sample t-test indicate that there exist significant mean difference between the base line scores and scores on consecutive first line, second line and third line assessments on the study variables.

Table 1: Mean Scores of baseline assessment and 3 post assessments

\begin{tabular}{|l|l|l|l|l|}
\hline Variables & $\begin{array}{l}\text { Base line } \\
\text { assessment }\end{array}$ & $\begin{array}{l}\mathbf{1}^{\text {st }} \\
\text { assessment }\end{array}$ & $\begin{array}{l}\mathbf{2}^{\text {nd }} \text { line } \\
\text { assessment }\end{array}$ & $\begin{array}{l}\text { 3rd line } \\
\text { assessment }\end{array}$ \\
\hline Personal care and appearance (PA) & 64.43 & 66.57 & 69.14 & 71.57 \\
\hline Food management (FM) & 43.00 & 48.00 & 53.71 & 58.00 \\
\hline $\begin{array}{l}\text { Household tasks and responsibility } \\
\text { (HR) }\end{array}$ & 30.00 & 38.71 & 46.29 & 50.29 \\
\hline Community and leisure (CL) & 30.14 & 33.86 & 41.43 & 44.43 \\
\hline Sexuality (S) & 44.86 & 46.14 & 49.71 & 49.87 \\
\hline Work (W) & 31.14 & 37.57 & 45.86 & 50.00 \\
\hline Functional literacy (FL) & 19.29 & 32.14 & 40.29 & 48.43 \\
\hline Social communication (SC) & 48.57 & 51.29 & 56.57 & 60.00 \\
\hline
\end{tabular}

Table 1 indicate the mean scores of baseline assessment and 3 post line assessments. From the mean scores of all the different dimensions under study, it can be seen that the mean score has gradually increased from baseline through third line assessment. It can be noticed that the scale is indeed sensitive to behavioural changes over time. 
Table 2. Comparison of baseline assessment scores and first line assessment

\begin{tabular}{|c|c|c|c|c|c|}
\hline \multirow{2}{*}{\multicolumn{2}{|c|}{ Variables }} & \multicolumn{4}{|c|}{ Paired Differences } \\
\hline & & \multirow{2}{*}{\begin{tabular}{|r|} 
Mean \\
-2.143 \\
\end{tabular}} & \multirow{2}{*}{\begin{tabular}{|l|} 
Std. Deviation \\
2.116 \\
\end{tabular}} & \multirow{2}{*}{\begin{tabular}{|l|}
$\mathbf{t}$ \\
2.680
\end{tabular}} & \multirow{2}{*}{\begin{tabular}{|l} 
Sig.(2-tailed) \\
$.037 *$
\end{tabular}} \\
\hline Pair 1 & PA1 - PA2 & & & & \\
\hline Pair 2 & FM1 - FM2 & -5.000 & 4.619 & 2.864 & $.029 *$ \\
\hline Pair 3 & HR1 - HR2 & -8.714 & 6.020 & 3.830 & $.009 * *$ \\
\hline Pair 4 & CL1 - CL2 & -3.714 & 2.984 & 3.293 & $.017 *$ \\
\hline Pair 5 & S1 - S2 & -1.286 & 1.380 & 2.465 & $.049 *$ \\
\hline Pair 6 & W1 - W2 & -6.429 & 5.623 & 3.025 & $.023 *$ \\
\hline Pair 7 & FL1 - FL2 & -12.857 & 11.682 & 2.912 & $.027 *$ \\
\hline Pair 8 & SC1 - SC2 & -2.714 & 7.064 & 1.017 & .349 \\
\hline
\end{tabular}

** Significant at 0.01 level

*significant at 0.05 level

Table no. 2 shows the comparison of baseline assessment with post first line assessment. The personal care and appearance includes self dependent in routine personal hygiene, performs exercises, sleeps 6-8 hours at night, the individual follows the dosage and timings of medicine as per prescription and tells at least one negative effect for each of hazardous substances or situation. The t value for personal care and appearance is 2.680; which is found significant at 0.05 level. The domain food management includes sets table/ spreads mat and places utensils in order, removes the utensils and cleans the table / mat, capacity to remove stones / unwanted particles from rice, capacity to wash utensils with soap, cleaning kitchen, able to identify and collect needful raw materials to use the stove, and cook required food items. The t value of food management is 2.864 and which is found significant at 0.05 level. The household tasks and responsibility includes the ability to perform the household activities on a regular basis as a part of responsibility. The t value of household tasks and responsibility is 3.830 and which is found highly significant at 0.01 level. The domain of community and leisure includes the ability of the individual to access community resources and indulge in leisure activities. The $t$ value of community and leisure is 3.293 and which is found significant at 0.05 level. The domain of sexuality includes the capacity of the individual to resist the sexual abuses, fulfils sexual desires following norms and basic knowledge about sexuality. The t value of sexuality is 2.465 and which is found significant at 0.01 level. The domain of work includes ability to follow work timings and sequence of work instructions, to follow all safety rules, and ability to perform work. The t value of work is 3.025 and which is found less significant at 0.05 level. The domain of functional literacy includes the managing of money, identifying address, information, makes payment. The $t$ value of functional literacy is 2.192 and which is found significant at 0.05 level. The domain of social communication includes capacity to use statements, ability to tell likes and dislikes, greets others. The $t$ value of social communication is 1.017 and which is not statistically significant. The results indicate that the training is indeed effective as they show significant mean difference except in the dimension social communication. It is very interesting to know 
that all the other dimensions of competencies have improved within three months of intervention at a statistically significant level.

Table 3. Comparison of baseline assessment scores and second line assessment

\begin{tabular}{|l|l|l|l|l|l|}
\hline \multicolumn{2}{|l|}{ Variables } & \multicolumn{3}{|c|}{ Paired Differences } \\
\cline { 3 - 6 } \multicolumn{2}{|l}{} & Mean & Std. Deviation & t & Sig. (2-tailed) \\
\hline Pair 1 & PA1 - PA3 & -4.714 & 6.102 & 2.044 & $.017^{*}$ \\
Pair 2 & FM1 - FM3 & -10.714 & 7.410 & 3.826 & $.009^{* *}$ \\
Pair 3 & HR1 - HR3 & -16.286 & 10.594 & 4.067 & $.007^{* *}$ \\
Pair 4 & CL1 - CL3 & -11.286 & 6.626 & 4.506 & $.004^{* *}$ \\
Pair 5 & S1 - S3 & -4.857 & 3.805 & 3.378 & $.015^{*}$ \\
Pair 6 & W1 - W3 & -14.714 & 7.952 & 4.896 & $.003^{* *}$ \\
Pair 7 & FL1 - FL3 & -21.000 & 14.166 & 3.922 & $.008^{* *}$ \\
Pair 8 & SC1 - SC3 & -8.000 & 9.327 & 2.269 & .064 \\
\hline
\end{tabular}

The above table no. 3 shows the comparison of baseline assessment with second line assessment. The $t$ value for personal care is 2.044 and which is found significant at 0.05 level. The $t$ value of food management is 3.826 and which is found highly significant at 0.01 level. The $t$ value of household tasks and responsibility is 4.067 and which is found highly significant at 0.01 level. The t value of community and leisure is 4.506 and which is found highly significant at 0.01 level. The $t$ value of sexuality is 3.378 and which is found significant at 0.05 level. The t value of work is 4.896 and which is found highly significant at 0.01 level. The t value of functional literacy is 3.922 and which is found highly significant at 0.01 level. The t value of social communication is 2.269 and which is not significant. The results indicate that the training is highly effective in the development of all dimensions except social communication. Thus vocational training has enhanced the competencies of mild mentally challenged adults with 6 months training.

Table 4. Comparison of baseline assessment scores and third line assessment

\begin{tabular}{|c|c|c|c|c|c|c|}
\hline \multicolumn{2}{|c|}{ Variables } & \multicolumn{5}{|c|}{ Paired Differences } \\
\hline & & \multirow{2}{*}{ Mean } & \multirow{2}{*}{$\begin{array}{l}\text { Std. } \\
\text { Deviation }\end{array}$} & \multirow{2}{*}{\begin{tabular}{|ll} 
Std. & Error \\
Mean &
\end{tabular}} & & \\
\hline & & & & & $\mathbf{t}$ & Sig. (2-tailed) \\
\hline Pair 1 & PA1 - PA4 & -7.143 & 8.707 & 3.291 & 2.170 & $.003 * *$ \\
\hline Pair 2 & FM1 - FM4 & -15.000 & 12.000 & 4.536 & 3.307 & $.016^{*}$ \\
\hline Pair 3 & HR1 - HR4 & -20.286 & 12.038 & 4.550 & 4.459 & $.004 * *$ \\
\hline Pair 4 & CL1 - CL4 & -14.286 & 6.800 & 2.570 & 5.558 & $.001 * *$ \\
\hline Pair 5 & S1 - S4 & -4.714 & 4.461 & 1.686 & 2.796 & $.031 *$ \\
\hline Pair 6 & W1 - W4 & -18.857 & 11.261 & 4.256 & 4.430 & $.004^{* *}$ \\
\hline Pair 7 & FL1 - FL4 & -29.143 & 20.211 & 7.639 & 3.815 & $.009 * *$ \\
\hline Pair 8 & SC1 - SC4 & -11.429 & 9.484 & 3.585 & 3.188 & $.019 *$ \\
\hline
\end{tabular}


The above table no. 4 shows the comparison of baseline assessment with third line assessment. The $t$ value for personal care is 2.170 and which is found highly significant at 0.01 level. The $t$ value of food management is 3.307 and which is found significant at 0.05 level. The $t$ value of household tasks and responsibility is 4.459 and which is found highly significant at 0.01 level. The t value of community and leisure is 5.558 and which is found highly significant at 0.01 level. The $t$ value of sexuality is 2.796 and which is found significant at 0.05 level. The t value of work is 4.430 and which is found highly significant at 0.01 level. The t value of functional literacy is 3.815 and which is found highly significant at 0.01 level. The t value of social communication is 3.188 and which is found significant at 0.05 level. The nine months training was highly effective in improving the competency dimensions under study. It is interesting to find the significant mean difference on social communication too after the completion of the training. Thus vocational training has enhanced the competencies of mild mentally challenged adults.

In India, attention to the vocational training of the mentally challenged has gained special importance since the enactment of the Person with Disabilities Act of 1995 (Jeyachandran, P. et. al. 2013). Yet, there is a serious need to go a long way in creating awareness through research and education: so that people can correct their misconceptions and differently abled can know about service facilities available for them. On the light of the present study it can be seen that by a systematic vocational training, mentally challenged persons will have a wide range of opportunities to seek employment in different situations.

\section{SUMMARY}

The present study aimed at exploring the impact of vocational training in the competencies of mild mentally challenged adults. Vocational rehabilitation course for a period of 9 months has provided as intervention on a sample of eight mild mentally challenged adults. The tool used for this purpose was Behavioral Assessment Scales for Adult Living - Mental Retardation (BASAL $-\mathrm{MR}$ ). The data were analysed using paired sample t test. The results clearly indicate that the vocational training has tremendous impact in enhancing the competencies of mild mentally challenged adults during the process of transition from school to work. It is highly recommended to provide vocational training for mild mentally challenged individuals as it definitely help them to use their maximum potentialities and thus to lead a dignified life in all aspects.

\section{REFERENCES}

Braun K.V.N., Alissop M.Y., \& Lollar D., (2006). A multi-dimensional approach to the transition of children with developmental disabilities into young adulthood: The acquisition of adult social roles. Disability and Rehabilitation, 28 (15): 915 -928. Retrieved from http://www.tandfonline.com/doi/full, on 5, 10, 2015.

Gargiulo, R. M., (2015). Special Education in Contemporary Society: An Introduction to Exceptionality, Birminghan: University of Alabama.

Grossman, H. J., (1983). Classification in mental retardation, Washington , DC: American Association on Mental deficiency. 
Harris, J.C., (2006). Intellectual disability: understanding its development, causes, classification, evaluation, and treatment, New York, NY: Oxford university Press.

http://censusindia.gov.in/Census_And_You/disabled_population.aspx,.Retrieved on 19-10-2015

Jeyachandran, P., Gadkari, J. P., \& Mishra, S.K., (2013) Status of Disability in India, New Delhi: RCI.

Mukhopadhyay, A., (2010). Principles of Vocational Training Part -2, New Delhi: Kanishka Publishers.

Peshawwaria, R., Menon, D., Bailey, D., Skinner, D., Ganguly, R., \& Rajshekar, Ch., (2000). Behavioural assessment scales for adult living - Mental retardation, Secunderabad: NIMH.

Schalock, R. L., Borthwick-Duffy S.A., Bradley V.J., Buntinx W. H. E., Coulter D. L.,...Yeager M.H., (2010). Intellectual Disability: Definition, Classification, and Systems of Supports, Washington (DC): AAID.

Thressiakutty, A.T., \& Govinda Rao L., (2001). Transition of persons with mental retardation from school to work - a guide, Secunderbad: NIMH.

Winzer, M.A., (1993), The history of special education: from isolation to integration, Washington, DC: Gallaudet University Press. 